\title{
Prenatal Exposure to Antiandrogen Flutamide Affects Androgen Receptor (AR) Expression in Postnatal Ovarian Development in Pig*
}

\author{
Małgorzata DuRLEJ, Iwona WIECIECH, Paulina WĘGRZYN, and Maria SŁOMCZYŃSKA
}

Accepted October 5, 2011

\begin{abstract}
Durlej M., Wieciech I., WęGrzyn P., SŁomczyńska M. 2012. Prenatal exposure to antiandrogen flutamide affects androgen receptor (AR) expression in postnatal ovarian development in pig. Folia biologica (Kraków) 60: 27-33.

The following study was undertaken to localize androgen receptors (ARs) in various structures of the porcine ovary after prenatal exposure to antiandrogen flutamide. In utero treatment by antiandrogens may have adverse effects on reproductive function in immature and adult animals. Flutamide was injected into pregnant swines between days 20 and 28 (GD20) or 80 to 88 (GD80) of gestation. The ovaries were collected from treated animals and from control ones (non-treated) at two different points of development: from immature and adult pigs. Immunoexpression of AR was determined for preantral and antral follicles and for stroma cells. Immunostaining showed that AR expression in immature animals was unaffected in the primary follicles, while in the preantral and antral follicles the AR level fluctuated depending on day of treatment as well as on analyzed tissue. In adult animals, the immunoexpression of AR slightly decreased in antral follicles independently on the day of flutamide treatment. Therefore, AR expression in postnatal life may be affected by in utero exposure to antiandrogen flutamide.
\end{abstract}

Key words: Androgen receptor, flutamide, ovary, pig.

Matgorzata DurLeJ, Iwona WIECIECH, Paulina WęGRZYN, Maria SŁOMCZYŃSKA, Department of Endocrinology, Institute of Zoology, Jagiellonian University, Gronostajowa 9 , 30-387 Kraków, Poland.

E-mail:malgorzata.durlej@uj.edu.pl maria.slomczynska@uj.edu.pl

The ovary has two important roles which depends on a succession of multiple integrated processes in female reproduction (LENIE \& SMITZ 2009). During the process of folliculogenesis the ovary produces fertilizable gametes and is an important site of steroid production that directly participates in folliculogenesis through endogenously expressed receptors and indirectly affects ovarian cyclicity through regulation of the neuroendocrine system. In mammals the ovary is controlled by endocrine and neural factors (WALTERS et al. 2008). Ovarian steroid hormones produced locally also regulate folliculogenesis through modulation of gonadotropin and growth factor activities. During antral follicle growth, theca cells predominantly secrete aromatizable androgens which accumulate within follicular fluid. Granulosa cells of all mammalian species examined to date express the AR and direct, AR-mediated activity has been impli- cated in the control of folliculogenesis through mechanisms that involve both FSH (WANG et al. 2001) and IGF1 (HICKEY et al. 2004, 2005).

Fully grown oocytes are arrested in the diploten stage of the first meiotic prophase, and the maturation of meiosis is triggered in vivo by a hormonal stimulus (FAN \& SUN 2004). Androgens were shown to be involved in promoting oocyte maturation in mouse (JAMNONGJIT \& HAMMES 2006), and could potentially trigger porcine oocyte meiotic resumption, which is mediated by intra-oocyte AR (Li et al. 2008). Hormones such as testosterone and dihydrotestosterone influences cell growth and differentiation by regulating specific target gene expression after binding to the androgen receptor (AR), a member of the steroid receptor superfamily (LAMB et al. 2001). Antiandrogens flutamide or bicalutamide work by inhibiting endogenous androgens from activating AR. Fluta- 
mide is a non-steroidal, pure anti-androgenic compound which binds $\mathrm{AR}$ and blocks androgen action (TEVELL et al. 2006).

A previous study revealed the presence of AR in the porcine fetal ovaries at different days of prenatal life. The study reported by BUREK et al. (2007) revealed that androgens may play a regulatory role in developing fetal ovary, as they are present in stroma cells surrounding and supporting the egg nests. The days of pregnancy selected for the experiment are critical for ovarian development. Day 20 is close to the time of implantation and the ovary is not differentiated yet, while at day 80 the formation of primordial follicles occurs. It is well known from our earlier papers, that exposure to flutamide during fetal development may result in defective expression of certain proteins (FSHR, Cx43) during postnatal life (DURLEJ et al. 2011a; 2011b). As those genes are androgen regulated, it could be assumed that differences in their expression level might be a result of changes in AR protein level/activity caused by flutamide treatment. However, the question remains whether in postnatal life the changes of expression of AR could be observed. Hence, the aim of this study was to localize AR protein immunologically in ovarian follicles of immature and adult pigs following prenatal flutamide exposure.

\section{Material and Methods}

\section{Animals and tissue collection}

All procedures were performed in accordance with the Polish legal requirements, under the license given by the National Commission of Bioethics at the Jagiellonian University, Kraków, Poland (No. 4/2008).

The study involved six pregnant crossbred pigs (Large White x Polish Landrace). They were divided into three groups. The first group served as a control, gilts of the second group were treated with flutamide (2-methyl-N-[4-nitro-3'-(trifluoromethyl)-phenyl]propamide) (Sigma-AldrichChemical Co., St. Louis, MO, USA) between gestational days 20-28 (GD20), and gilts of the third group between days $80-88$ (GD80). Flutamide (50 mg/kg body weight) was dissolved in corn oil and was given as subcutaneous injections at every second day of gestation. Female offspring from control $(\mathrm{n}=3)$ and flutamide-treated pigs ( $\mathrm{n}=3$ for GD20 and GD80) were maintained until immaturity and ovarian samples were collected from three-month-old pigs. Simultaneously, part of the animals from each group $(\mathrm{n}=3$ for control, GD20 and GD80) were bred until sexual maturity and ovarian tissues were obtained from nine-month-old ones (mature). Ovariectomy was performed under general anesthesia. Gestational days were chosen on the basis of literature data (FOSTER \& HARRIS 2005) and our previous studies (BUREK et al. 2007; KNAPCZYK et al. 2008). Control animals were exposed only to corn oil.

\section{AR immunolocalization}

The ovarian samples were fixed in $10 \%$ buffered formalin overnight. Then, samples were dehydratated in an increasing gradient of ethanol and equilibrated with xylene prior to embedding in paraplast (Monoject Scientific Devision of Sherwood Medical, St. Lousis, MO, USA). Paraplast sections were cut by microtome $(5 \mu \mathrm{m})$, mounted on slides, deparaffinized in xylene and rehydrated through a series of alcohol dilutions. Sections were subjected to a microwave antigen retrieval technique by incubation in $0.01 \mathrm{M}$ citrate buffer $(\mathrm{pH}$ 6.0) in a microwave oven at full power for $3 \times 4 \mathrm{~min}$. Endogenous peroxidase activity was blocked with $0.3 \% \mathrm{H}_{2} \mathrm{O}_{2}$ in TBS (Tris buffered saline, $\mathrm{pH}$ 7.4) for $20 \mathrm{~min}$. After the treatment, the sections were left for $30 \mathrm{~min}$ in the buffer for cooling. To prevent nonspecific reactions, sections were incubated with 5\% normal goat serum (Sigma-Aldrich, St. Louis, MO, USA) for $30 \mathrm{~min}$ at room temperature. Thereafter, tissue sections were incubated overnight at $4^{\circ} \mathrm{C}$ with the primary rabbit polyclonal antibody antiAR (1:2000, SantaCruz). Negative control sections were incubated with non-immune goat serum instead of androgen receptor antibody. After washing in TBS buffer for amplification, of the primary antibody reaction the secondary goat biotinylated antibody (1:300, Vector Lab.) was placed for $1.5 \mathrm{~h}$ and ABC Complex/HPR (avidinbiotinylated horseradishperoxidase complex; 1:100; Vector Lab.) was used.

The reaction product was visualized using TBS containing $0.01 \% \mathrm{H}_{2} \mathrm{O}_{2}, 0.05 \%$ diaminobenzidine (DAB; Sigma Aldrich) and 0.07\% imidazole. Finally, slides were dehydrated and mounted on DPX (Fluka Chemie GmbH, Buchs).

\section{AR immunostaining evaluation and statistical analysis}

For specific AR immunostaining analysis photomicrographs were taken using a Nikon Eclipse E200 microscope attached to Coolpix 5400 digital camera system and then quantified by a videodensitometric analysis using ImageJ software (National Institutes of Health, Bethesda, MD, USA). At least eight different sections from each investigated animal were examined. For the intensity of immunoreaction in stroma cells, five randomly chosen microscopic fields from each section were 

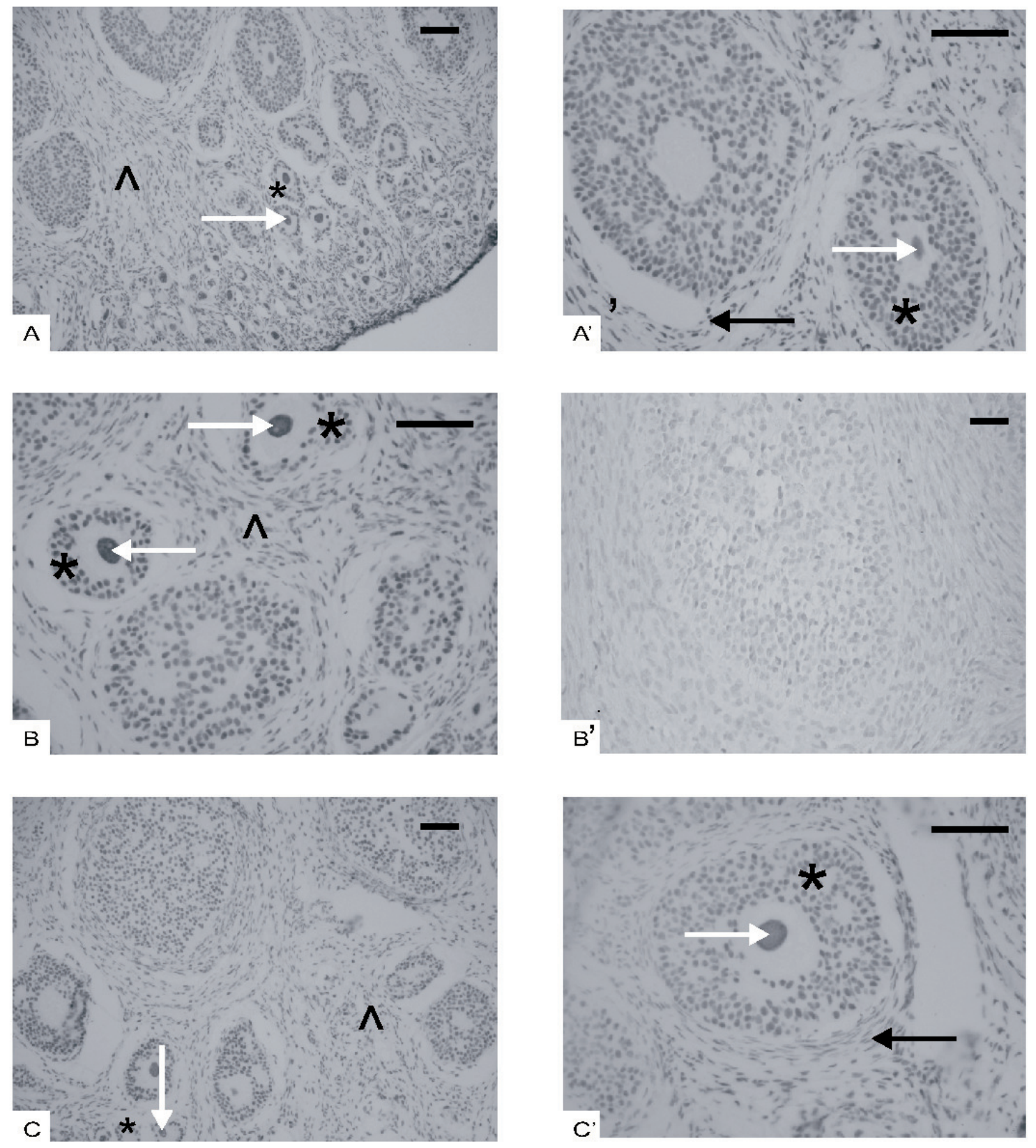

Fig. 1. Immunohistochemical localization of androgen receptor (AR) in primary (one layer of cuboidal granulosa cells) and preantral (more than one layer of granulosa cells) follicles of immature porcine ovaries following exposure to flutamide: A, A' - control group; B - flutamide treatment on gestational days 20-28; C, C' - flutamide treatment on gestational days 80-88. Positive reaction was observed in the nuclei of all primary and preantral follicle components: oocytes (white arrows), granulosa cells $(*)$, theca cells (black arrows) and in the nuclei of stroma cells $\left({ }^{\wedge}\right)$. B' - negative control, scale bar $=100 \mu \mathrm{m}$.

measured. Primary, preantral and antral follicles, all observed in the sections, were quantified. Measurements were repeated twice by two independent observers. The intensity of the immunohistochemical reaction was expressed as relative optical density (ROD) of diaminobenzidine brown reaction products (SMOLEN 1990). Statistical analysis was performed using the STATISTICA 5.1 program (StatSoft Imc, Tulsa, OK, USA). ANOVA test was used to analyze statistical differ- ences and Tukey's test was used to determined differences between groups. Statistical significances were set at $\mathrm{P}<0.01$.

\section{Results}

In ovaries of immature pigs, AR immunoexpression was examined in primary (one layer of cuboidal granulosa cells), preantral (more than one layer 
of granulosa cells) and antral follicles. In ovaries of adult animals AR immunostaining was analyzed in antral follicles. Immunolocalization of AR was observed in all investigated animals. However, the intensity of reaction differed in the examined groups.

\section{Immature animals}

In the primary follicles no differences in AR expression were observed in flutamide treated animals (Fig. 1). The intensity of staining was unaffected by flutamide treatment in experimental groups in oocytes and granulosa cells (Fig. 4A). At this stage of follicle development it was difficult to analyze theca cells which were not well differentiated.

Immunohistochemistry demonstrated that AR was present in preantral follicles in GD20, GD80 and control groups (Fig. 1). The intensity of immunostaining increased in oocytes from GD20 $(\mathrm{P}<0.01)$, and in theca cells from GD80, while the intensity of staining decreased in granulosa cells from GD80 group (Fig. 4B).

In the antral follicles AR protein was decreased in granulosa, theca and stroma cells in the GD80 experimental group while no statistically significant differences were demonstrated in GD20 animals (Figs $2 \& 4 C$ ).

\section{Adult animals}

In large antral follicles AR protein was observed in granulosa and theca cells (Fig. 3). However, the intensity of staining decreased in flutamide treated pigs in comparison to control animals (Fig. 4D).

Quantitative evaluation of the intensity of the immunohistochemical reaction in all ovarian compartments (Figs 4A-D) was expressed as relative optical density (ROD). Significant differences were detected between oocyte, granulosa and stroma cells of flutamide treated animals GD20 in comparison to the control group and GD80 $(\mathrm{P}<0.01)$.

\section{Discussion}

The current study is the first which demonstrated changes in the expression of AR in the ovaries of pigs treated with flutamide during fetal life.

$\mathrm{AR}$ is a ligand activated nuclear transcription factor which regulates the functions of many organs. In the embryo, androgens stimulate male differentiation and determine morphogenesis of the genital tract. The genomic effect of androgens is mediated via nuclear ARs and androgens have the ability to up- and down-regulate their own receptor. The study by BUREK et al. (2007) shows that in the developing fetal ovary androgen receptor immunoreaction is limited predominantly to stroma cells surrounding and suppoting the egg nests. Immunolabeling was observed in developing follicles in pregranulosa cells (day 90 p.c.) independent of their origin from surface epithelial cells or intraovarian rete. Granulosa cells of ovarian preantral follicles collected from 1 day-old neonatal piglets are AR-positive (BUREK et al. 2007). However, the lack of AR in granulosa cells of preantral follicles was observed in the ovaries of neonatal rats (our unpublished observation).

Previous research revealed that exposure to flutamide during gestation led to alteration in AR mRNA levels at least in preantral and large antral follicles of adult pigs (DURLEJ et al. 2011b). However, there was no influence of flutamide exposure on $\mathrm{Cx} 43$ expression in the gonads of neonatal (DURLEJ et al. 2011c) and prepubertal pigs (KOPERA et al. 2010).

Prenatal testosterone deficiency (as a result of antiandrogen action) results in postnatal changes in ovarian morphology and function. As shown here, exposure to flutamide in utero results in changes of AR protein level in animals in neonatal life as well as in immature and adult pigs. Observed changes are not very dramatic, and in some tissues the increase of immunostaining level can be observed while in other compartments, a decrease was documented. There is no doubt that exposure to flutamide during fetal life can affect AR expression in fetal life as well as in different developmental points after delivery. Although differences are statistically relevant, they fluctuate during development. Flutamide has been shown to block effectively the action of both T and DHT by competing at the level of the androgen receptor whereas it has no effect on T or DHT biosynthesis (IMPERATO-MCGINLEY et al. 1992). Flutamide promotes AR translocation to the nucleus and binding to DNA but no transcription is observed (TRUSS et al. 1994). Single cell analysis of live cells during hormone addition shed light on the rapid changes in AR function that result in nuclear translocation (MARCELLI et al. 2006).

Several genes are known to be involved in embryonic gonad development and sexual differentiation in large mammals such as the pig. Some of them may be regulated by androgens (MCCOARD et al. 2001). In order to regulate transcription, nuclear receptors must exist as a part of large multiprotein complexes. AR-dependent transcriptional activity is modulated by co-regulators. Multiple factors are considered to regulate the expression of several steroid hormone receptors in some cells, emphasizing the importance of balance of physiological androgen and estrogen for the differentiation of many organs during embryogenesis 

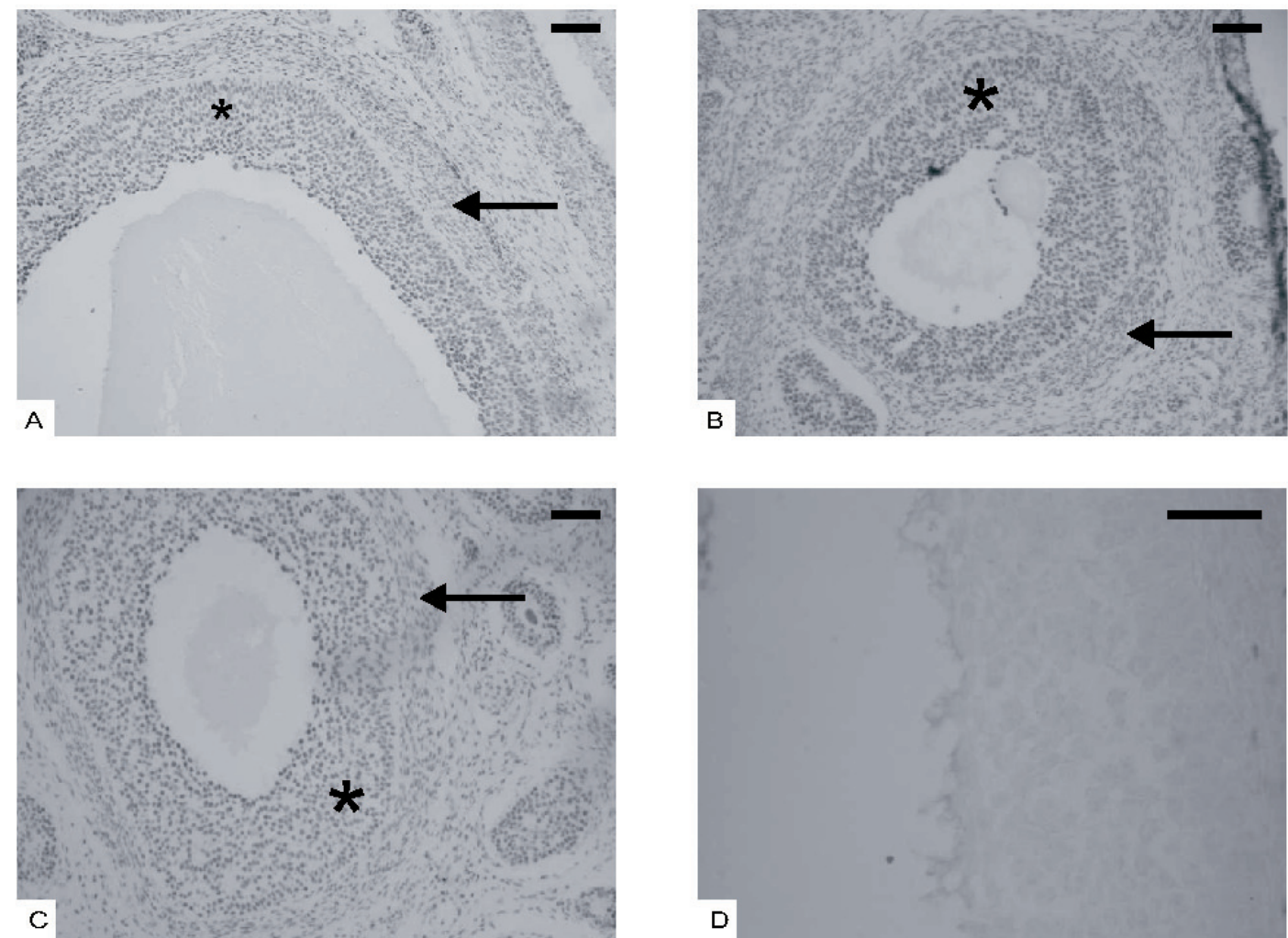

Fig. 2. Immunohistochemical localization of androgen receptor (AR) in antral follicles of immature porcine ovaries following exposure to flutamide: A - control group; B - flutamide treatment on gestational days 20-28; C - flutamide treatment on gestational days $80-88$.

Positive reaction was observed in the nuclei of granulosa cells $\left(^{*}\right)$ and theca cells (black arrows) of antral follicles. D negative control, scale bar $=100 \mu \mathrm{m}$.
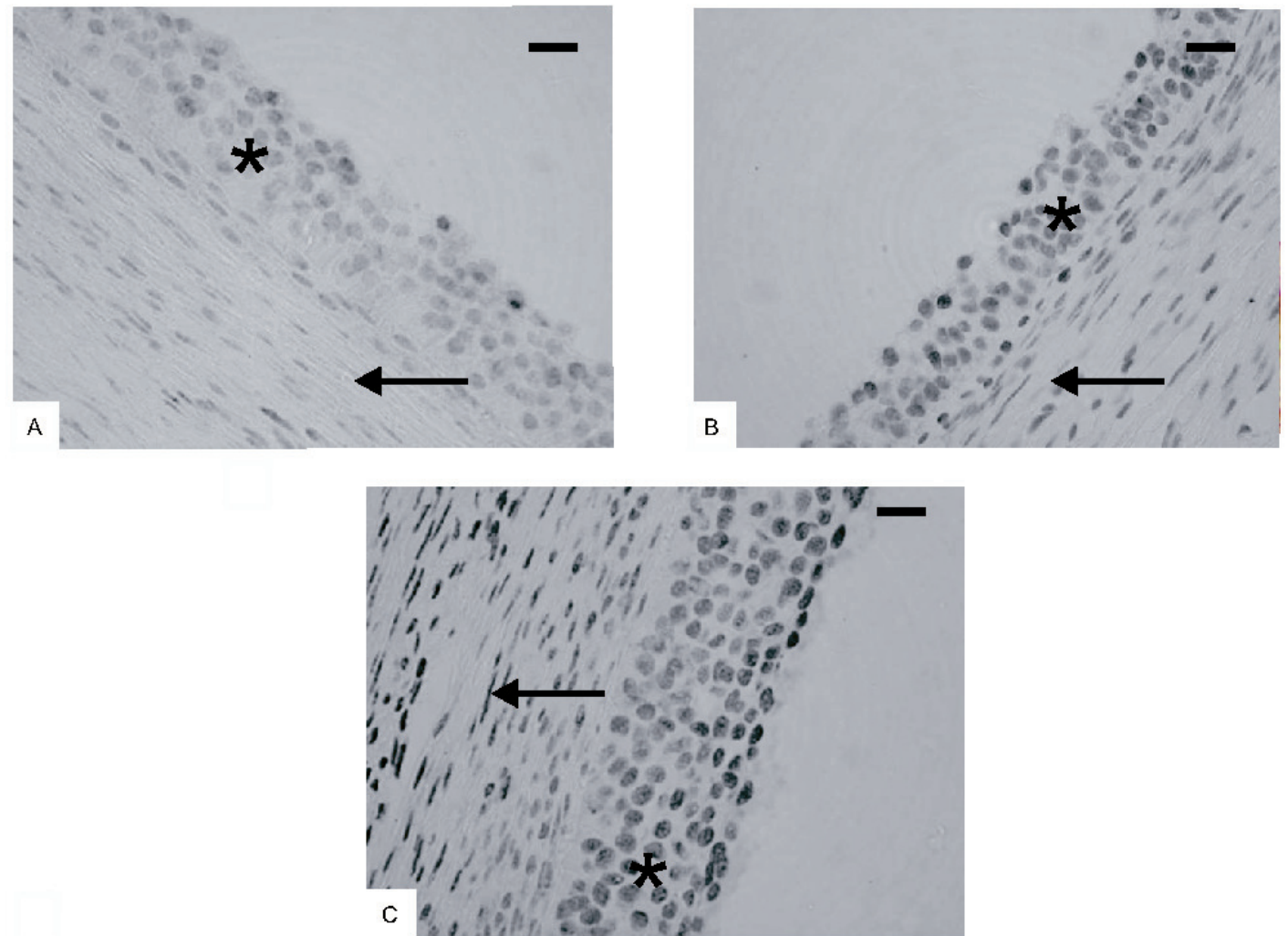

Fig. 3. Immunohistochemical localization of androgen receptor (AR) in antral follicles of mature porcine ovaries following exposure to flutamide: A - control group; B - flutamide treatment on gestational days 20-28; C - flutamide treatment on gestational days $80-88$

Positive reaction was observed in the nuclei of granulosa cells $(*)$ and theca cells (black arrows) of antral follicles, scale bar $=$ $100 \mu \mathrm{m}$. 

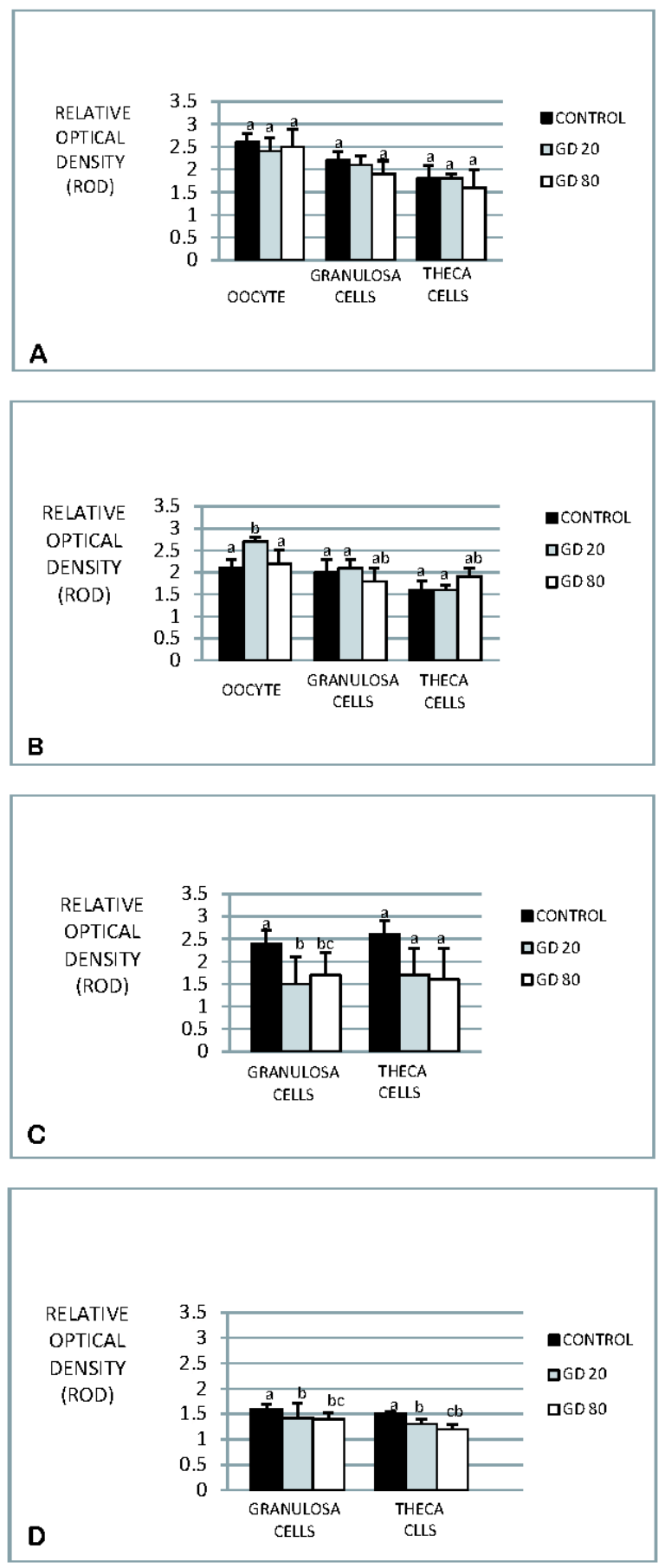

Fig. 4. The intensity of androgen receptor (AR) immunostaining expressed as relative optical density (ROD) in: primary follicles (A), preantral follicles (B) and antral follicles (C) of immature pig ovaries and antral follicles of adult porcine ovaries (D) exposed to flutamide at different days of gestation versus control. Values are means $\pm \mathrm{SD}$. Different letter superscripts indicate differences at $\mathrm{P}<0.01$.

(HUGHES et al. 2001). Exposure to androgen excess in utero induces irreversible changes in gonadotropin secretion and results in disruption of reproductive endocrine and ovarian function in adulthood (FORSDIKE et al. 2007). An abnormal- ity in early follicle development in ovaries with polycystic ovary syndrome may be the effect of androgens. Prenatal exposure to androgens not only caused abnormality in gonadotropin secretion, but also exerted a direct effect on the early stages of folliculogenesis which is supported by recent data from fetal sheep ovaries as well as from studies in other species. A reduced proportion of primordial and an increased proportion of growing follicles was the result of exposure to high concentrations of androgen (STECKLER et al. 2005). The increase in AR immunostaining in the ovarian stroma and granulosa of primordial and primary follicles of sheep fetus under testosterone (or DHT) treatment was documented. Therefore, AR is involved in the pathway of androgen action (ORTEGA et al. 2009). Studies using a culture system demonstrated that testosterone stimulates primary to secondary follicle transition via AR-dependent mechanism (YANG \& FORTUNE 2006).

It is not clear how a decreased level of testosterone during the fetal life influence the level of AR in the adult ovary and how it is involved in its dysfunction. The epigenetic modification of key ovarian regulatory genes has been implicated (ORTEGA et al. 2009). Sex steroids have the ability to influence the methylation of DNA and AR acetylation (VOTTERO et al. 2006; XUE et al. 2007). Thus, the non-genomic action of androgens should also be taken into consideration. Further experiments showing the AR level in fetal ovaries of pigs treated in utero with flutamide are required.

In conclusion, our data show that androgens regulate their own receptor and the most visible effect is observed in adult animals. Exposure to antiandrogen during fetal life results in alteration of some androgen-regulated genes in adulthood.

\section{References}

BureK M., DUdA M., KNAPCZYK K., KOZIOROWSKi M., SLOMCZYNSKA M. 2007. Tissue-specific distribution of the androgen receptor (AR) in the porcine fetus. Acta Histochem. 109: 358-365.

DURLEJ M., KNAPCZYK-STWORA K., DUDA M., GALAs J., SLOMCZYNSKA M. 2011a. The expression of FSH receptor (FSHR) in the neonatal porcine ovary and its regulation by flutamide. Reprod. Dom. Anim. 46: 377-384.

Durlej M., KNAPCZYK-STWORA K., Duda M., KoPERA-Sobota I., HeJMEJ A., BILINSKA B., SLOMCZYNSKA M. 2011b. Prenatal and neonatal exposure to the antiandrogen flutamide alters connexin 43 gene expression in adult porcine ovary. Domest. Anim. Endocrinol. 40: 19-29.

DURLEJ M., KOPERA I., KNAPCZYK-STWORA K., HEJMEJ A., DUdA M., KOZIOROWSKI M., SLOMCZYNSKA M., BILINSKA B. 2011 c. Connexin 43 gene expression in male and female gonads of porcine offspring following in utero exposure to an anti-androgen, flutamide. Acta Histochem. 113: 6-12.

FAN H. Y., SUN Q. Y. 2004. Involvement of MAPK cascade during oocyte maturation and fertilization in mammals. Biol. Reprod. 70: 535-547. 
FORSDIKE R. A., HARDY K, BULL L, STARKL J.,WEBBER L. J., STUBBS S., RoBinson J. E., FRANKS S. 2007. Disordered follicle development in ovaries of prenatally androgenized ewes. J. Endocrinol. 192: 421-428.

FOSTER P. M., HARRIS M. W. 2005. Changes in androgenmediated reproductive development in male rat offspring following exposure to a single oral dose of flutamide at different gestational ages. Toxicol. Sci. 85: 1024-1032.

Hickey T. E., Marrocco D. L., Amato F., Ritter L. J., NORMAN R. J., GILCHRIST R. B., ARMSTRONG D. T. 2005. Androgens augment the mitogenic effects of oocyte secreted factors and growth differentiation factor 9 on porcine granulosa cells. Biol. Reprod. 73: 825-832.

Hickey T. E., MARRocCO D. L., Gilchrist R. B., NORMAN R. J., ARMSTRONG D. T. 2004. Interactions between androgen and growth factors in granulosa cell subtypes of porcine antral follicles. Biol. Reprod. 71: 45-52.

Hughes I. A., Lim H. N., Martin H., Mongan N. P., DoveY L., AHmed S. F., HAWkins J. R. 2001. Developmental aspects of androgen action. Mol. Cell. Endocrinol. 185: $33-41$.

IMPERATO-MCGINLEY J., SANCHEZ R. S., SPENCER J. R., YeE B., DarRacotT N., VAughan E. 1992. Finasteride and the antiandrogen flutamide on prostate comparison of the effects of the 5a-reductase inhibitor and genital differentiation: dose-response studies. Endocrinology 131: $1149-1156$

JAMNONGJTT M., HAMMES S. 2006. Ovarian steroids: the good, the bad, and the signals that raise them. Cell Cycle 5: $1178-1183$.

KnAPCZYK K., Duda M., DuRlej M., Galas J., KozioROWSKI M., SLOMCZYNSKA M. 2008. Expression of estrogen receptor $\alpha(E R \alpha)$ and estrogen receptor $\beta(E R \beta)$ in the ovarian follicles and corpora lutea of pregnant swine. Domest. Anim. Endocrinol. 35: 170-179.

Kopera I., Durlej M., HeJMEJ A., KNAPCZYK-STwORA K., DUDA M., SLOMCZYNSKA M., KOZIOROWSKI M., BILINSKA B. 2010. Effects of pre- and post-natal exposure to flutamide on connexin 43 expression in testes and ovaries of prepubertal pigs. Eur. J. Histochem. 54: 67-72.

LAMB D. J., Weigel N. L., MeRCElli M. 2001. Androgen receptors and their biology. Vitam. Horm. 62: 199-230.

LENIE S., SMITZ J. 2009. Functional AR signalling is evident in an in vitro mouse follicle culture bioassay that encompasses most stages of folliculogenesis. Biol. Reprod. 80: 685-695.

Li M., Ai J-S., Xu B-Z., Xiong B., Yin S., Lin S-L., Hou Y., CHEN D-Y., SCHATTEN H., SUN Q-Y. 2008. Testosterone potentially triggers meiotic resumption by activation of intra-oocyte SRC and MAPK in porcine oocytes. Biol. Reprod. 79: 897-905.
MARCELli M., StenOIEN D. L., SZAFran A. T., SimeOni S., Agoulnik I. U., Weigel N. L., MORAn T., MiKIC I., PRICE J. H., MANCINI M. A. 2006. Quantifying effects of ligands on androgen receptor nuclear translocation, intracellular dynamics, and solubility.J. Cell Bioch. 98: 770-788.

McCoArd S. A., Wise T. H., FAHRENKRUNG S. C., Ford J. J. 2001. Temporal and spatial localization patterns of Gata4 during porcine gonadogenesis. Biol. Reprod. 65: 366-374.

Ortega H. H., Salvetti N. R., Padmanabhan V. 2009. Developmental programming: prenatal androgen excess disrupts ovarian steroid receptor balance. Reproduction 137: 865-877.

SMOLEN A. J. 1990. Image analytic techniques for quantification of immunocytochemical staining in the nervous system. (In: Methods in Neurosciences. P. M. Conn ed. Academic Press, New York): 208-229.

Steckler T., Wang J., Bartol F. F., Roy S. K., PADMANABHAN V. 2005. Fetal programming: prenatal testosterone treatment causes intrauterine growth retardation, reduces ovarian reserve and increases ovarian follicular recruitment. Endocrinology 146: 3185-93.

TEVell A., LenNernas H., JONSSON M., NORLin M., LENNERNAS B., BONDESSON U. 2006. Flutamide metabolism in four different species in vitro and identyfication of flutamide metabolites in human patient urine by high performance liquid chromatography/tandem mass spectrometry. Drug. Metab. Dispos. 34: 982-992.

TRUSS M., BARTSCH J., BEATO M. 1994. Antiprogestins prevent progesterone receptor binding to hormone responsive elements in vivo. Proc. Natl. Acad. Sci. USA 91: 11333-11337.

VotTero A., CAPElletti M., Giuliodori S., Viani I., ZiVERI M., NERI T. M., BERNASCONI S., GHIZZONI L. 2006. Decreased androgen receptor gene methylation in premature pubarche: a novel pathogenetic mechanism? J. Clin. Endocrinol. Metab. 91: 968-72.

Walters K. A., Allan C. M., Handelsman D. J. 2008. Androgen actions and the ovary. Biol. Reprod. 78: 380-389.

WANG H., ANDOH K., HagiWARA H., XiaOWEI L., KiKUCHI N., ABE Y., YAMADA K., FATima R., MizUnuma H. 2001. Effect of adrenal and ovarian androgens on type 4 follicles unresponsive to FSH in immature mice. Endocrinology 142: 4930-4936.

Xue Q., Lin Z., Cheng Y. H., Huang C. C., Marsh E., Yin P., Milad M. P., Confino E., Reierstad S., InNES J., BULUN S. E. 2007. Promoter methylation regulates estrogen receptor 2 in human endometrium and endometriosis. Biol. Reprod. 77: 681-7.

YANG M. Y., FORTUNE J. E. 2006. Testosterone stimulates the primary to secondary follicle transition in bovine follicles in vitro. Biol. Reprod. 75: 924-32. 